\title{
Decrements in Stiffness are Restored within 10 min
}

Authors

Affiliation
T. Mizuno, M. Matsumoto, Y. Umemura

Chukyo University, School of Health and Sport Sciences, Toyota, Japan
Key words

- static stretching

- muscle-tendon unit

- plantar flexor muscle

short duration

human accepted after revision

September 05, 2012

Bibliography

DOI http://dx.doi.org/

10.1055/s-0032-1327655

Published online:

November 9, 2012

Int J Sports Med 2013; 34:

484-490 @ Georg Thieme

Verlag KG Stuttgart · New York ISSN 0172-4622

\section{Correspondence}

\section{Takamasa Mizuno}

School of Health and Sport Sciences, Laboratory for Exercise Physiology and Biomechanics Chukyo University

School of Health and Sport Sciences

Chukyo University

101 Tokodachi kaizu-cho

470-0393 Toyota

Japan

Tel.: + 81/565/46 1211

Fax: +81/565/46 1272

taka.mizuno82@gmail.com

\section{Abstract}

$\nabla$

The purpose of this study was to clarify the temporal course of stiffness in the muscle-tendon unit after stretching. In 11 male participants, displacement of the myotendinous junction on the gastrocnemius medialis muscle was measured ultrasonographically during the passivedorsiflexion test, with the ankle was passively dorsiflexed at $1 \% \mathrm{~s}$ to the end of the range of motion. Passive torque, representing resistance to stretch, was also measured using an isokinetic dynamometer. On 4 different days, passive-dorsiflexion tests were performed before and immediately, 5,10 or $15 \mathrm{~min}$ after stretching, which

\section{Introduction}

$\nabla$

Stretching before exercise is a common practice, and the effects reportedly include improved joint range of motion (ROM) and prevention of injury $[34,40]$. However, decreased muscle-tendon unit (MTU) stiffness as a result of static stretching may have major effects on subsequent performance. Various studies have demonstrated that static stretching decreases stiffness of the MTU $[21,22,25,27,35]$, representing one factor in increasing joint ROM $[7,27,41,43]$. This increase in joint ROM is important in some dynamic sports in which enhanced static flexibility would be expected to affect performance, such as rhythmic gymnastics. However, the decrease in stiffness of the MTU that results from static stretching represents one factor decreasing maximum muscle strength [36]. This phenomenon is known as "stretching-induced force deficit", and some reports have also described decreases in isometric muscle strength $[3,8]$, concentric muscle strength [5-7], muscle endurance [29], sprinting speed [42], and vertical jump height [15]. Decreased stiffness of the MTU after static stretching thus comprised dorsiflexion to end range of motion and holding that position for $1 \mathrm{~min}, 5$ times. As a result, end range of motion and passive torque at end range of motion were significantly increased after stretching $(P<0.05)$ as compared with each previous value. Although stiffness of the muscletendon unit was significantly decreased immediately and $5 \mathrm{~min}$ after stretching $(P<0.05)$, this change recovered within $10 \mathrm{~min}$. These results suggest that static stretching for $5 \mathrm{~min}$ results in significantly increased range of motion over $30 \mathrm{~min}$, but significant decreases in stiffness of the muscle-tendon unit returned to baseline levels within 5-10 min. of unambiguous results may be differences in stretching time [24]. To reduce the risk of injury after stretching, sufficient decreases in stiffness of the MTU are important [14,38], and are believed to require four or five 60-s stretches $[19,20,22,25,28,35]$. Stretching times shorter than this are considered ineffective in preventing injury $[30,39]$. This means that at least $4 \mathrm{~min}$ of static stretching is required to lower the risk of injury by decreasing stiffness of the MTU in the target muscle.

As stretching is generally performed $15-60 \mathrm{~min}$ before exercise [44], accurate knowledge of changes over time in the stiffness of the MTU as a result of stretching is important. Ryan et al. [35] reported that stiffness of the MTU decreased 
immediately after $2 \mathrm{~min}, 4 \mathrm{~min}$, and $8 \mathrm{~min}$ of stretching, but that the effects of stretching disappeared within $10 \mathrm{~min}$ after $2 \mathrm{~min}$ of stretching, and within $20 \mathrm{~min}$ after $4 \mathrm{~min}$ and $8 \mathrm{~min}$ of stretching. Mizuno et al. [26] found that although maximal angle of dorsiflexion was increased after $5 \mathrm{~min}$ of ankle stretching and this effect was maintained for over $30 \mathrm{~min}$, the decrease in stiffness of the MTU disappeared within $15 \mathrm{~min}$, indicating that the increase in end ROM immediately after stretching is attributable to both decreased stiffness of the MTU and increased "stretch tolerance", while the increase in end ROM at more than $15 \mathrm{~min}$ after stretching is largely attributable to increased "stretch tolerance". To the best of our knowledge, however, few previous studies have systematically investigated changes in decreased stiffness of the MTU over time. Taking into account the fact that the effect of $5 \mathrm{~min}$ of static stretching disappears within $15 \mathrm{~min}$ [26], a focused investigation on the shorter period up to $15 \mathrm{~min}$ immediately after stretching would be highly advantageous to elucidate the retention time of the effect of stretching on stiffness of the MTU. The purpose of this study was thus to systematically clarify the time course for stiffness of the MTU. This work was conducted under the hypothesis that decrements in stiffness of the MTU would be retained over some interval, but would return to baseline within $15 \mathrm{~min}$.

\section{Materials and Methods}

$\nabla$

\section{Participants}

15 healthy men volunteered for the study, and the final cohort comprised 11 men (mean ( \pm standard deviation (SD)) age, $23.3 \pm 3.0$ years; height, $172.2 \pm 6.8 \mathrm{~cm}$; weight, $64.4 \pm 7.5 \mathrm{~kg}$ ) who could be dorsiflexed $>15^{\circ}$ in all passive dorsiflexion tests over the course of 4 test days, as stiffness values of the MTU were determined at $5^{\circ}, 10^{\circ}$ and $15^{\circ}(\odot$ Fig. 1 b). The 4 volunteers who could not be dorsiflexed $>15^{\circ}$ in $\geq 1$ test were excluded from all analyses. All participants were recreationally active, but not involved in any structured physical training regime. No participants reported any history of recent musculoskeletal injuries or neuromuscular diseases specific to the lower limb. Written informed consent was obtained from all participants. The study protocols were approved by the Human Subjects Committee of Chukyo University Graduate School of Health and Sport Sciences, and complied with their requirements for human experimentation. The present study was performed in accordance with the ethical standards of the International Journal of Sports Medicine [13].

\section{Experimental protocol}

A randomized, repeated-measures, cross-over design (time [prevs. post-stretching] $\times$ rest interval [immediately vs. $5 \mathrm{~min}$ versus $10 \mathrm{~min}$ vs. $15 \mathrm{~min}]$ ) was used to clarify the time course of stiffness of the MTU. Participants visited the laboratory on 5 occasions, each separated by more than $24 \mathrm{~h}$. Participants completed all experimental trials within 2 weeks. The first visit was a familiarization trial and the subsequent 4 visits were experimental trials. Before each set of measurements, participants were instructed to rest in a sitting position for $15 \mathrm{~min}$ in our laboratory. The first passive-dorsiflexion test was performed before stretching. During the passive-dorsiflexion test, we measured passive torque and displacement of the myotendinous junction (MTJ) at different joint angles, and end ROM of the ankle joint and electromyographic (EMG) activities of the medial and lateral heads of the gastrocnemius muscle. After the first passive-dorsiflexion test, static stretching was performed. Participants were then instructed to rest in a sitting position for various intervals before performing the second passive-dorsiflexion test. We designed 4 different rest intervals of 0 (immediately), 5, 10 and $15 \mathrm{~min}$, with testing on 4 different days. The order of these sessions was randomized.

\section{Passive-dorsiflexion test}

To determine passive torque, displacement of the MTJ, end ROM and EMG, each participant underwent 1 passive-dorsiflexion test before stretching and after the rest interval (immediately, 5 , 10 and $15 \mathrm{~min}$ post-stretching). The passive-dorsiflexion test was performed using an approach similar to that adopted by our previous study [26]. Participants were secured to the isokinetic machine (Biodex System3; Biodex, NY, USA) with the knee in full extension, and the footplate fixed to the right foot. The lateral malleolus was aligned with the axis of the dynamometer. In this study, all reported ankle angles were assessed as the angle of the footplate, and ankle angle was defined as $0^{\circ}$ when the footplate was perpendicular to the floor. Values were defined as positive for dorsiflexion. Passive end ROM was determined using an approach similar to the method adopted by Morse et al. [27]. In this method, the foot of the participant was passively and isokinetically dorsiflexed at a speed of $1 \%$ from $-30^{\circ}$ to the angle at which the participant felt discomfort and stopped the dynamometer by activating a safety trigger. Maximal angle of the footplate was defined as the end ROM. In this process, passive torque generated on the footplate was also determined at ankle angles of submaximal $\left(0^{\circ}, 5^{\circ}, 10^{\circ}\right.$ and $\left.15^{\circ}\right)$ and maximal dorsiflexion. Throughout the passive-dorsiflexion test, participants were requested to relax completely and not offer any voluntary resistance. Passive torque and ankle joint angle were converted from analog to digital at a sampling rate of $1.5 \mathrm{kHz}$ (LX-10; TEAC, Tokyo, Japan).

To be consistent with our previous study (26), stiffness values of the MTU $\left(\mathrm{Nm} /{ }^{\circ}\right)$ were calculated using a second-order polynomial regression model that was fit to the passive torque-angle curves at the 4 points of $0^{\circ}, 5^{\circ}, 10^{\circ}$ and $15^{\circ}$. Stiffness values of the MTU were calculated as the slope of the polynomial fit passive torque-angle curves. Stiffness values of the MTU were determined at $5^{\circ}, 10^{\circ}$ and $15^{\circ}(\odot$ Fig. $\mathbf{~ b ~ b ) . ~}$

B-Mode ultrasonography (LOGIQ P5; GE Healthcare, CT, USA) was used to determine displacement of the MTJ for gastrocnemius medialis during the passive-dorsiflexion test. The MTJ was visualized as a longitudinal ultrasonic image using a $4.5-\mathrm{cm}$, 12.0-MHz linear-array probe (12 L probe; GE Healthcare), which was synchronized to the passive torque and joint angle outputs. The probe was secured to the skin using a specially made frame made of styrol. Displacement of the MTJ was measured as the value relative to a reflective marker placed between the skin and ultrasonic probe as a landmark. Ultrasonic images were recorded on videotape at $30 \mathrm{~Hz}$ (SR-VSI30; Victor, Kanagawa, Japan). Displacement of the MTJ was analyzed using software we developed. Displacement of the MTJ was manually traced using this software, which was made with Visual C\# (Microsoft, WA, USA) and DirectShow (Microsoft). In this study, the gastrocnemius muscle was elongated, and the MTJ was moved distally, because the ankle joint was dorsiflexed from $-30^{\circ}$ to end ROM (o Fig. 1a).

The reliability of ultrasound measurement with the ankle joint in a neutral position $\left(0^{\circ}\right)$ to $15^{\circ}$ of dorsiflexion was evaluated in 


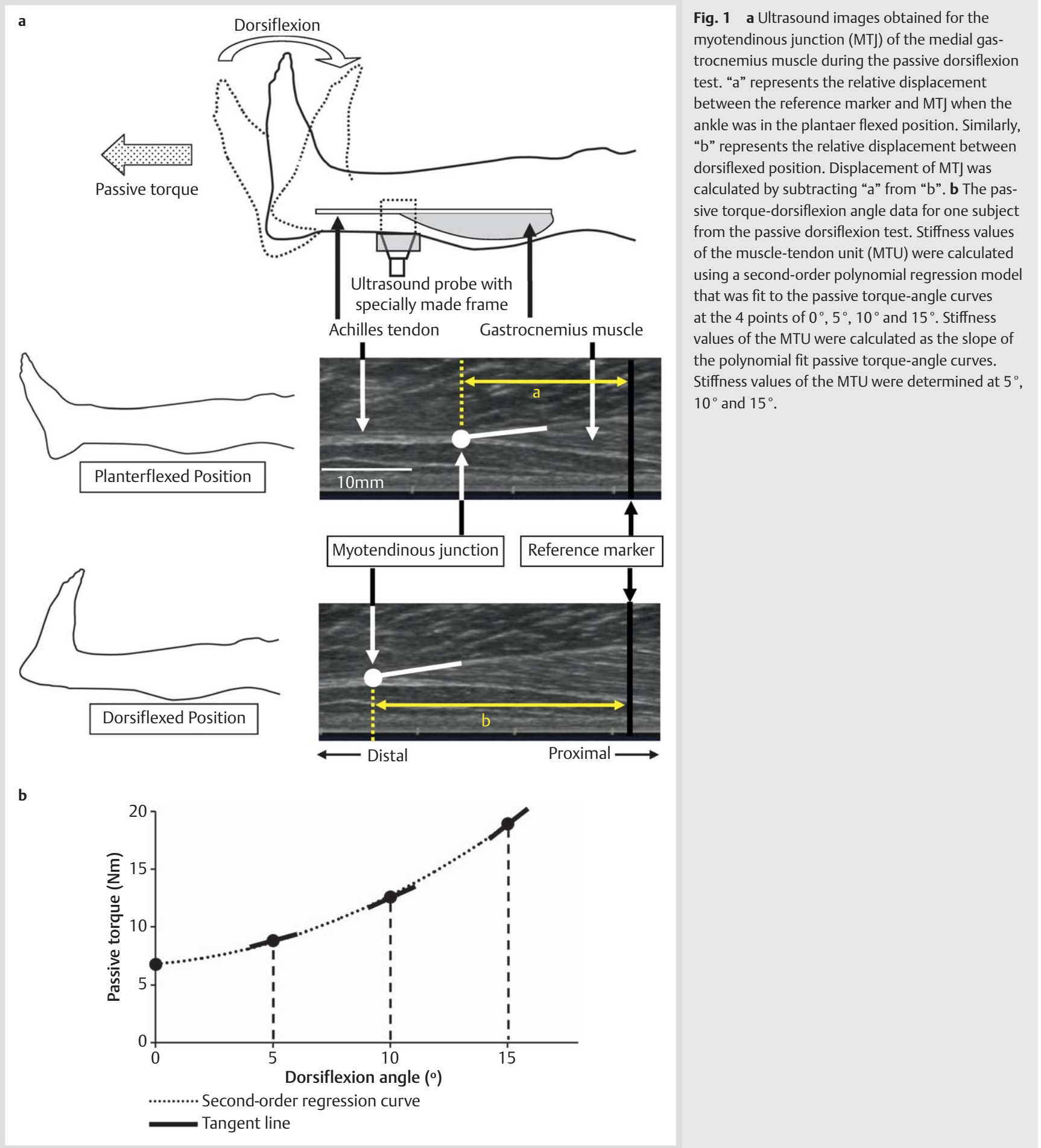

1 subject by measuring displacement of the MTJ. The coefficients of variation (SD/mean) was $4.7 \%$.

\section{Static stretching}

Repeated static stretching was performed using the isokinetic dynamometer in the same fashion as the passive dorsiflexion test. Static stretching was administered to the right lower leg of each participant. The leg was secured on an isokinetic machine with the knee in full extension. The footplate attached to the isokinetic machine was fixed securely to the right foot of each participant and passively dorsiflexed at a constant velocity of $1^{\circ} / \mathrm{s}$ from $30^{\circ}$ of plantar flexion to a position of maximal dorsiflexion angle that provoked a sensation in the triceps surae muscle similar to a static stretch manoeuvre without pain and the participant stopped the dynamometer by activating the safety trigger. This position was then held at a constant angle for $1 \mathrm{~min}$. Thereafter, the footplate was returned to a position of $30^{\circ}$ of plantar flexion. This stretching procedure was repeated 5 times. Maximal dorsiflexion angle was reassessed at each dorsiflexion. Throughout stretching, participants were requested to relax completely and not offer any voluntary resistance. 


\section{EMG}

To ensure the passive-dorsiflexion test was truly passive, we measured EMG activities using bipolar, $13 \mathrm{~mm}, \mathrm{Ag} / \mathrm{AgCl}$ surface electrodes (S\&ME; Biolog, Tokyo, Japan) placed on the most prominent bulge of the gastrocnemius medialis and gastrocnemius lateralis muscles with a $25-\mathrm{mm}$ interelectrode distance. EMG activity was recorded with a band width of $5 \sim 2000 \mathrm{~Hz}$. EMG signals were transmitted to a digital data recorder at a sampling rate of $1.5 \mathrm{kHz}$. To remove any potential contribution of gastrocnemius medialis or gastrocnemius lateralis muscle contraction during dorsiflexion, we monitored EMG tracings $<50 \mu \mathrm{V}$ above baseline during the passive stretch cycles of passive-dorsiflexion tests [9]. This level of EMG activity corresponds to approximately $2 \%$ maximal voluntary contraction [23] and ensures minimal activation of gastrocnemius medialis or gastrocnemius lateralis muscles during passive-dorsiflexion tests [11]. In this study, mean values for all test sessions in terms of root mean square EMG values of gastrocnemius medialis and gastrocnemius lateralis during passive-dorsiflexion test were $7.3 \pm 2.6 \mu \mathrm{V}$ and $8.0 \pm 2.2 \mu \mathrm{V}$ for the initial $10^{\circ}$ and $7.5 \pm 3.1 \mu \mathrm{V}$ and $9.3 \pm 4.4 \mu \mathrm{V}$ for the final $5^{\circ}$, respectively.

\section{Statistics}

All data are reported as mean \pm SD. In this study, all measurement parameters were assumed to show normal distribution. Homogeneity of the variance assumption was assessed by the assumption of sphericity. Parameters that did not meet the assumption of sphericity were corrected for this violation using the Greenhouse-Geisser adjustment. A 3-way analysis of variance (ANOVA) (time [pre-stretch vs. post-stretch] $\times$ rest interval [immediately vs. $5 \mathrm{~min}$ versus $10 \mathrm{~min}$ vs. $15 \mathrm{~min}] \times$ angle $\left[0^{\circ}\right.$ versus $5^{\circ}$ vs. $10^{\circ}$ vs. $15^{\circ}$ ]) was used to analyze submaximal passive torque and submaximal displacement of the MTJ. A 3-way ANOVA (time [pre-stretch vs. post-stretch] $\times$ rest interval [immediately vs. $5 \mathrm{~min}$ vs. $10 \mathrm{~min}$ vs. $15 \mathrm{~min}] \times$ angle $\left[5^{\circ}\right.$ vs. $10^{\circ}$ vs. $15^{\circ}$ ]) was used to analyze stiffness values of the MTU. Two-way ANOVA (time [pre-stretch vs. post-stretch] $\times$ rest interval [immediately vs. $5 \mathrm{~min}$ vs. $10 \mathrm{~min}$ vs. $15 \mathrm{~min}$ ]) was used to analyze end ROM and passive torque at end ROM. When appropriate, followup analyses were performed using lower-order ANOVA and $t$ tests with Bonferroni corrections. The level of significance was set at $P<0.05$.

\section{Results \\ $\nabla$}

\section{End ROM}

No significant 2-way interaction (time x rest interval) and no main effect for rest interval were identified, but a significant main effect was seen for time. Stretching increased end ROM $(P<0.05)(\odot$ Fig. 2a).

\section{Passive torque at end ROM}

No significant 2-way interaction (time $\times$ rest interval) and no main effect for rest interval were identified, but a significant main effect was seen for time. Stretching increased passive torque at end $\operatorname{ROM}(P<0.05)(\otimes$ Fig. $2 \mathbf{b})$.

\section{Submaximal passive torque}

No significant 3-way interaction (time $\times$ rest interval $\times$ angle) and no significant 2-way interactions for time $\times$ angle or rest interval $\times$ angle were seen, but a significant 2-way interaction for
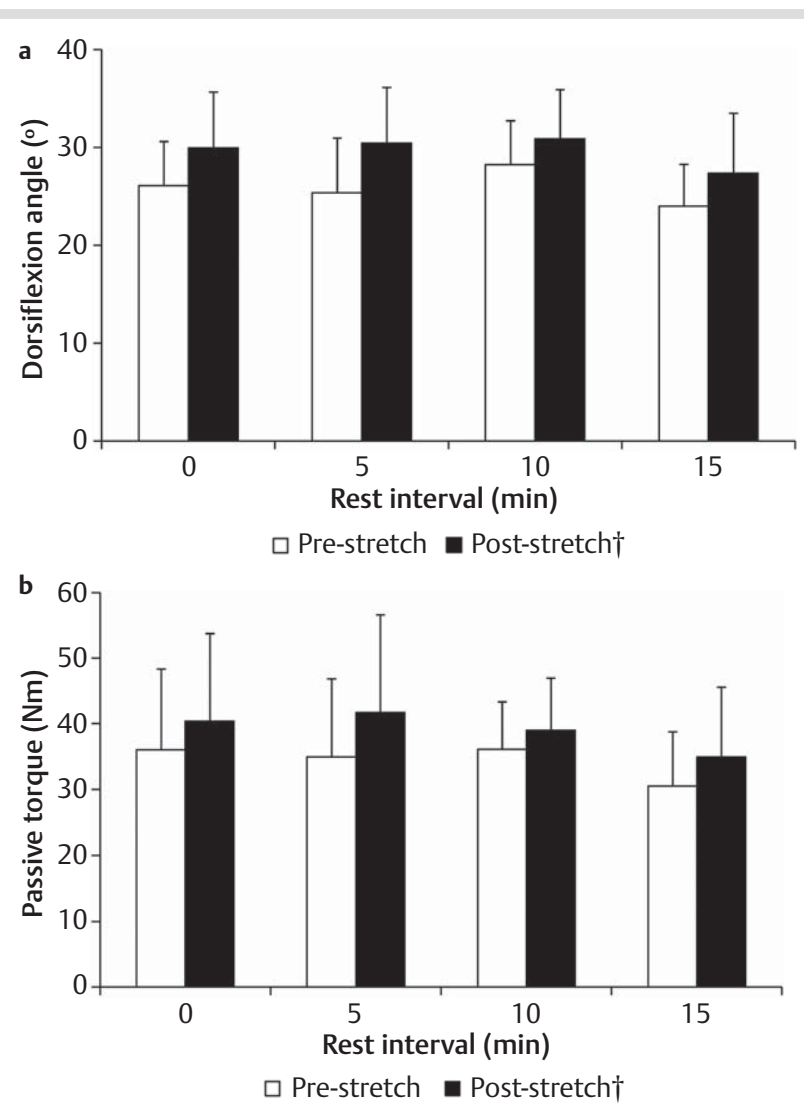

Fig. 2 Stretching-induced changes in end range of motion (ROM) a and passive torque at end ROM $\mathbf{b} .{ }^{\dagger} A$ significant main effect was seen for time on passive torque at end ROM $(P<0.05)$. Data are expressed as mean \pm standard deviation.

Table 1 Passive torque $(\mathrm{Nm})$ at $0^{\circ}, 5^{\circ}, 10^{\circ}$ and $15^{\circ}$, before and after stretching.

\begin{tabular}{|lllll}
\hline $\begin{array}{l}\text { Rest interval } \\
\text { (min) }\end{array}$ & \multicolumn{5}{c}{ Dorsiflexion angle $\left({ }^{\circ}\right)$} \\
\hline $\begin{array}{l}\text { Immediately } \\
\text { pre }\end{array}$ & $7.5 \pm 1.4$ & $10.2 \pm 2.2$ & $13.8 \pm 3.3$ & $19.3 \pm 4.7$ \\
\hline post* & $6.7 \pm 1.5$ & $9.1 \pm 2.3$ & $12.3 \pm 3.0$ & $16.8 \pm 4.0$ \\
\hline 5 & & & & \\
\hline pre & $7.4 \pm 1.6$ & $10.3 \pm 2.4$ & $14.0 \pm 3.7$ & $19.4 \pm 5.4$ \\
\hline post & $7.7 \pm 2.1$ & $10.2 \pm 3.0$ & $13.6 \pm 4.1$ & $17.9 \pm 5.4$ \\
\hline 10 & & & & \\
\hline pre & $6.9 \pm 1.0$ & $9.1 \pm 1.3$ & $12.5 \pm 2.0$ & $17.1 \pm 2.8$ \\
\hline post & $6.9 \pm 1.4$ & $9.2 \pm 1.8$ & $12.3 \pm 2.7$ & $16.8 \pm 4.0$ \\
\hline 15 & & & & \\
\hline pre & $6.9 \pm 1.0$ & $9.1 \pm 1.3$ & $12.5 \pm 2.0$ & $17.1 \pm 2.8$ \\
\hline post & $6.9 \pm 1.4$ & $9.2 \pm 1.8$ & $12.3 \pm 2.7$ & $16.8 \pm 4.0$ \\
\hline
\end{tabular}

Values represent mean \pm SD. A significant interaction (time $\times$ rest interval) was seen ${ }^{*} P<0.05$ compared to before stretching

time $\times$ rest interval was identified. Post hoc analyses revealed that stretching decreased submaximal passive torque immediately after stretching $(P<0.05)$. However, no significant differences in submaximal passive torque were seen at 5,10 or $15 \mathrm{~min}$ after stretching ( $\bullet$ Table 1 ).

\section{Stiffness of the MTU}

No significant 3-way interaction (time $\times$ rest interval $\times$ angle) and no significant 2-way interactions for time $\times$ angle or rest inter- 


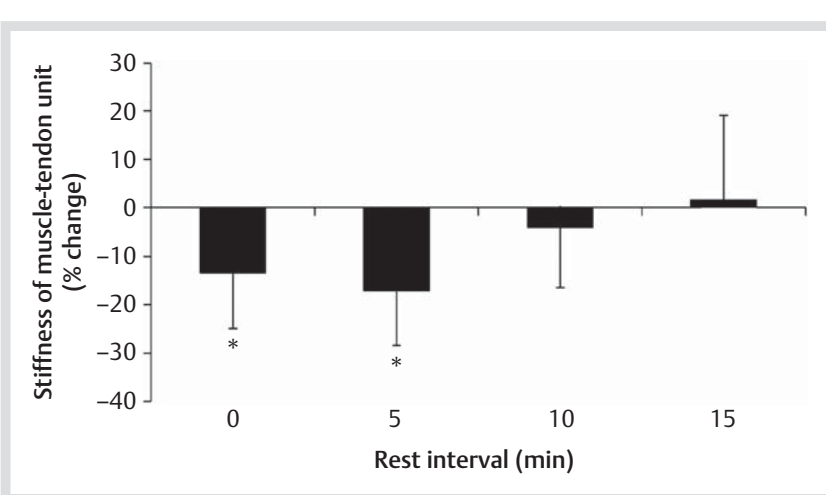

Fig. 3 Percent change in stiffness of the muscle-tendon unit (MTU) as a result of stretching. ${ }^{*}$ A significant 2 -way interaction (time $\times$ rest interval) was seen on stiffness of the MTU $(P<0.05)$. Data are expressed as mean \pm standard deviation.

Table 2 Displacement of myotendinous junction $(\mathrm{mm})$ at $0^{\circ}, 5^{\circ}, 10^{\circ}$ and $15^{\circ}$, before and after stretching.

\begin{tabular}{|c|c|c|c|c|}
\hline \multirow{2}{*}{$\begin{array}{l}\text { Rest interval } \\
\text { (min) }\end{array}$} & \multicolumn{4}{|c|}{ Dorsiflexion angle $\left({ }^{\circ}\right)$} \\
\hline & 0 & 5 & 10 & 15 \\
\hline \multicolumn{5}{|l|}{ Immediately } \\
\hline pre & $0 \pm 0$ & $2.5 \pm 0.9$ & $4.8 \pm 1.4$ & $7.1 \pm 1.5$ \\
\hline post & $0 \pm 0$ & $3.1 \pm 0.8^{*}$ & $5.9 \pm 1.3^{*}$ & $8.3 \pm 1.5^{*}$ \\
\hline \multicolumn{5}{|l|}{5} \\
\hline pre & $0 \pm 0$ & $3.1 \pm 0.7$ & $5.4 \pm 1.3$ & $7.5 \pm 1.8$ \\
\hline post & $0 \pm 0$ & $2.9 \pm 0.9$ & $5.7 \pm 1.5$ & $8.1 \pm 1.7^{*}$ \\
\hline \multicolumn{5}{|l|}{10} \\
\hline pre & $0 \pm 0$ & $2.8 \pm 0.6$ & $5.0 \pm 0.7$ & $7.0 \pm 1.1$ \\
\hline post & $0 \pm 0$ & $2.6 \pm 0.6$ & $4.8 \pm 0.6$ & $6.7 \pm 1.2$ \\
\hline \multicolumn{5}{|l|}{15} \\
\hline pre & $0 \pm 0$ & $3.0 \pm 0.9$ & $5.3 \pm 1.3$ & $7.5 \pm 1.9$ \\
\hline post & $0 \pm 0$ & $2.7 \pm 0.8$ & $5.6 \pm 1.6$ & $7.6 \pm 1.9$ \\
\hline
\end{tabular}

val $\times$ angle were seen, but a significant 2 -way interaction for time $\times$ rest interval was identified. Post hoc analyses revealed that stretching decreased submaximal passive torque for immediately and $5 \mathrm{~min}$ after stretching $(P<0.05$ each). However, no significant differences in submaximal passive torque were seen at 10 and $15 \mathrm{~min}$ after stretching ( $\mathrm{Fig} . \mathbf{3}$ ).

\section{Displacement of the MTJ}

A significant 3-way interaction (time $\times$ rest interval $\times$ angle) was noted. Post hoc testing revealed stretching increased displacement of the MTJ for immediately after stretching at $0^{\circ}, 5^{\circ}, 10^{\circ}$ and $15^{\circ}$, and for $5 \mathrm{~min}$ after stretching at $15^{\circ}(P<0.05$ each $)$. However, no significant differences in displacement of the MTJ were seen more than $10 \mathrm{~min}$ after stretching at any angle ( 0 Table 2).

\section{Discussion}

$\nabla$

The objective of this study was to elucidate the effective time for which decreased stiffness of the MTU is maintained as a result of $1 \mathrm{~min}$ of static stretching at maximal dorsiflexion repeated 5 times. We found that although stiffness of the MTU decreased after static stretching, this effect disappeared within $10 \mathrm{~min}$. In this study, all passive-dorsiflexion tests were performed passively, because EMG values of gastrocnemius medialis and gastrocnemius lateralis during passive-dorsiflexion test were $<50 \mu \mathrm{V}$ above baseline.

Our finding in this study, that 1 min of static stretching at maximal dorsiflexion repeated 5 times increased end ROM of the ankle, was consistent with the results of previous studies $[26,27]$. In the present study, end ROM increased significantly by $3.86 \pm 5.1^{\circ}$ immediately after static stretching compared with pre-stretching. Although the extent of the effect of static stretching on end ROM differed between individuals, this significant increase in end ROM was maintained $5 \mathrm{~min}\left(5.1 \pm 6.0^{\circ}\right), 10 \mathrm{~min}$ $\left(2.6 \pm 4.1^{\circ}\right)$, and $15 \mathrm{~min}\left(3.4 \pm 4.4^{\circ}\right)$ after stretching. In addition, a previous study showed the retention time of the effect of 5 minstretching on end ROM was $>30$ min, with no effect of stretching retained by $60 \mathrm{~min}$ [26]. The increase in end ROM immediately after and $15 \mathrm{~min}$ after stretching was around the same level as that seen in our previous study [26]. The observation in the present study that the increase in end ROM was maintained 15 min after stretching is also supported by the findings of Radford et al. [33], who reported that this effect is maintained for 5-30 min after static stretching.

In this study, the decrease in stiffness of the MTU disappeared within $10 \mathrm{~min}$ after stretching. The increase in passive torque at end ROM as a result of static stretching, however, was still maintained $15 \mathrm{~min}$ after stretching. End ROM increases after static stretching for 2 main reasons: 1 ) changes in mechanical characteristics of the MTU [20]; and 2) increased "stretch tolerance" $[7,41]$. The increase in end ROM immediately after and 5 min after stretching seen in our study was probably due to both these factors, with the increase in end ROM $10 \mathrm{~min}$ and $15 \mathrm{~min}$ after stretching due to increased "stretch tolerance" alone. This result was supported by previous studies suggesting that acute and long-term increases in maximal attainable end ROM are related to subject tolerance to stretch, rather than passive properties of the muscle $[20,22]$. The mechanisms underlying altered stretch tolerance remain unclear. However peripheral mechanisms such as afferent information from muscle, tendon and joint receptors may play a role and the potential involvement of central factors cannot be excluded [22].

The decrease in stiffness of the MTU observed in our study was probably mainly due to increased displacement of muscle. A number of tentative theories have been advanced to explain the mechanism underlying the decrease in stiffness of the MTU after static stretching, including increased tendon compliance [17], increased muscle fascicle length $[8,12]$, and changes in intramuscular connective tissue $[10,22,27]$. In the present study, displacement of muscle was increased significantly at $5^{\circ}, 10^{\circ}$, and $15^{\circ}$ dorsiflexion immediately after stretching, and at $15^{\circ}$ dorsiflexion 5 min after stretching. MTU length is the sum of muscle length and tendon length. In this study, therefore, displacement of muscle was increased (i.e., increment of muscle length) and MTU length was constant at the same angle of dorsiflexion before and after stretching, indicating decreased displacement of tendon (i.e., decrement of tendon length) after stretching. When muscle stiffness immediately after and 5 min after stretching was calculated by the same method used in our previous study [26], a tendency toward a reduction in muscle stiffness was observed immediately after stretching (about $22 \%$ decrease, from $2.2 \pm 1.0$ to $1.7 \pm 0.8 \mathrm{Nm} / \mathrm{mm}$ ) and $5 \mathrm{~min}$ after stretching (about $30 \%$ decrease, from $2.4 \pm 1.3$ to $1.6 \pm 0.6 \mathrm{Nm} / \mathrm{mm}$ ). This finding was consistent with the results described by Morse et al. [27] that although displacement of muscle increased and muscle 
stiffness decreased after stretching, no change in tendon stiffness occurred. This is inconsistent with the findings of Kubo et al. $[17,18]$, however, that tendon stiffness decreased after static stretching, and that changes in stiffness of the MTU are probably unrelated $(r=0.19)$ to tendon stiffness [16]. Working on the hypothesis that stiffness of the MTU is not the only factor affecting passive torque, which is also influenced by other factors including ligaments, joint capsules, connective tissue, and skin, and that the contribution of stiffness of the MTU is constant before and after stretching, decreased muscle stiffness may possibly result in increased displacement of the muscle, with stiffness of the MTU decreasing as a result, causing a reduction in passive torque. As one reason for the decrease in muscle stiffness, Purslow et al. [32] reported the perimysium as the main extracellular contributor to passive stiffness. Gajdosik et al. [10] also suggested that lengthening deformation of the connective tissue within the muscle belly (endomysium, perimysium and epimysium) could influence passive stiffness. The results of our study, however, suggest that changes in displacement of muscle and connective tissue are only short-term.

Decreased stiffness of the MTU due to static stretching is regarded as one factor in the subsequent decrease in muscle strength [36]. Several previous studies have investigated the effect of static stretching on subsequent muscle strength and exercise performance, with no change after static stretching reported by some authors [1] and a decrease described by others [3,8]. To the best of our knowledge, however, only a few reports have described improved exercise performance after static stretching. This reduction in maximum muscle strength after static stretching is known as a "stretching-induced force deficit," and 2 tentative theories have been proposed with respect to the mechanisms involved $[3,5,6,8,14]: 1)$ the neural factors, such as decreases in muscle activation; and 2) the mechanical factors, such as decreases in stiffness of the MTU. The reason the mechanical and contractive characteristics of the MTU cause a "stretchinginduced force deficit" is reportedly because stretching increases the length of the resting sarcomere, thus affecting the muscle strength/length relationship and/or sarcomere-shortening velocity $[5,8,14]$. The results of our study, however, suggest that even if a decrease in muscle strength occurs after $5 \mathrm{~min}$ of static stretching, this effect is only maintained for $\leq 10 \mathrm{~min}$. This is supported by the finding of Ryan et al. [36] that after $2 \mathrm{~min}, 4 \mathrm{~min}$, or 8 min of static ankle joint stretching and $15 \mathrm{~min}$ at rest, maximum muscle strength decreased immediately after stretching in all experiments, but this effect disappeared within $10 \mathrm{~min}$. In general, taking into consideration the fact that pre-exercise stretching is usually performed at least $10 \mathrm{~min}$ before the start of exercise, and that in practice the actual time spent stretching for a single site is shorter, the negative effects of static stretching on exercise performance are probably extremely small.

In conclusion, our results indicate that $1 \mathrm{~min}$ of static stretching at maximal dorsiflexion repeated 5 times can reduce stiffness in the MTU, but this effect disappears within $10 \mathrm{~min}$. This suggests the possibility that although decreased stiffness of the MTU after pre-exercise static stretching is believed to be one factor that can negatively affect performance, the actual effects may be almost non-existent.

\section{References}

1 Alpkaya $U$, Koceja $D$. The effects of acute static stretching on reaction time and force. J Sports Med Phys Fitness 2007; 47: 147-150

2 Amako M, Oda T, Masuoka K, Yokoi H, Campisi P. Effect of static stretching on prevention of injuries for military recruits. Mil Med 2003; 168: $442-446$

3 Behm DG, Button DC, Butt JC. Factors affecting force loss with prolonged stretching. Can J Appl Physiol 2001; 26: 261-272

4 Bixler B, Jones RL. High-school football injuries: effects of a posthalftime warm-up and stretching routine. Fam Pract Res J 1992; 12: 131-139

5 Cramer JT, Beck TW, Housh TJ, Massey LL, Marek SM, Danglemeier S, Purkayastha S, Culbertson JY, Fitz KA, Egan AD. Acute effects of static stretching on characteristics of the isokinetic angle - torque relationship, surface electromyography, and mechanomyography. J Sports Sci 2007; 25: 687-698

6 Cramer JT, Housh TJ, Weir JP, Johnson GO, Coburn JW, Beck TW. The acute effects of static stretching on peak torque, mean power output, electromyography, and mechanomyography. Eur J Appl Physiol 2005; 93: $530-539$

7 Evetovich TK, Nauman NJ, Conley DS, Todd JB. Effect of static stretching of the biceps brachii on torque, electromyography, and mechanomyography during concentric isokinetic muscle actions. J Strength Cond Res 2003; 17: 484-488

8 Fowles JR, Sale DG, MacDougall JD. Reduced strength after passive stretch of the human plantarflexors. J Appl Physiol 2000; 89: 11791188

9 Gajdosik RL, Vander Linden DW, Williams AK. Influence of age on length and passive elastic stiffness characteristics of the calf muscle-tendon unit of women. Phys Ther 1999; 79: 827-838

10 Gajdosik RL. Passive extensibility of skeletal muscle: review of the literature with clinical implications. Clin Biomech 2001; 16: 87-101

11 Gajdosik RL, Vander Linden DW, McNair PJ, Williams AK, Riggin TJ. Effects of an eight-week stretching program on the passive-elastic properties and function of the calf muscles of older women. Clin Biomech 2005; 20: 973-983

12 Halar EM, Stolov WC, Venkatesh B, Brozovich FV, Harley JD. Gastrocnemius muscle belly and tendon length in stroke patients and ablebodied persons. Arch Phys Med Rehabil 1978; 59: 476-484

13 Harriss DJ, Atkinson G. Update - ethical standards in sport and exercise science research. Int J Sports Med 2011; 32: 819-821

14 Herda TJ, Cramer JT, Ryan ED, McHugh MP, Stout JR. Acute effects of static versus dynamic stretching on isometric peak torque, electromyography, and mechanomyography of the biceps femoris muscle. J Strength Cond Res 2008; 22: 809-817

15 Holt $B W$, Lambourne $K$. The impact of different warm-up protocols on vertical jump performance in male collegiate athletes. J Strength Cond Res 2008; 22: 226-229

16 Kubo K, Kanehisa H, Fukunaga T. Is passive stiffness in human muscles related to the elasticity of tendon structures? Eur J Appl Physiol 2001; 85: 226-232

17 Kubo K, Kanehisa H, Fukunaga T. Effects of transient muscle contractions and stretching on the tendon structures in vivo. Acta Physiol Scand 2002; 175: 157-164

18 Kubo K, Kanehisa H, Kawakami Y, Fukunaga T. Influence of static stretching on viscoelastic properties of human tendon structures in vivo. J Appl Physiol 2001; 90: 520-527

19 Magnusson SP, Aagaard P, Nielson JJ. Passive energy return after repeated stretches of the hamstring muscle-tendon unit. Med Sci Sports Exerc 2000; 32: 1160-1164

20 Magnusson SP, Simonsen EB, Agaard P, Dyhre-Poulsen P, Mchugh MP, Kjaer $M$. Mechanical and physiological responses to stretching with and without preisometric contraction in human skeletal muscle. Arch Phys Med Rehab 1996; 77: 373-378

21 Magnusson SP, Simonsen EB, Aagaard P, Kjaer M. Biomechanical responses to repeated stretches in human hamstring muscle in vivo. Am J Sports Med 1996; 24: 622-628

22 Magnusson SP, Simonsen EB, Agaard P, Sorensen H, Kjaer M. A mechanism for altered flexibility in human skeletal muscle. J Physiol 1996; 497: 291-298

23 Mahieu NN, McNair P, Cools A, D'Haen C, Vandermeulen K, Witvrouw E. Effect of eccentric training on the plantar flexor muscle-tendon tissue properties. Med Sci Sports Exerc 2008; 40: 117-123

24 McHugh MP, Cosgrave $\mathrm{CH}$. To stretch or not to stretch: the role of stretching in injury prevention and performance. Scand J Med Sci Sports 2010; 20: 169-181

25 McHugh MP, Nesse M. Effect of stretching on strength loss and pain after eccentric exercise. Med Sci Sports Exerc 2008; 40: 566-573 
26 Mizuno T, Matsumoto M, Umemura $Y$. Viscoelasticity of the muscletendon unit is returned more rapidly than range of motion after stretching. Scand J Med Sci Sports 2011 In Press

27 Morse CI, Degens H, Seynnes OR, Maganaris CN, Jones DA. The acute effect of stretching on the passive stiffness of the human gastrocnemius muscle tendon unit. J Physiol 2008; 586: 97-106

28 Muir IW, Chesworth BM, Vandervoort AA. Effect of a static calf-stretching exercise on the resistive torque during passive ankle dorsiflexion in healthy subjects. J Orthop Sports Phys Ther 1999; 29: 106-115

29 Nelson AG, Kokkonen J, Arnall DA. Acute muscle stretching inhibits muscle strength endurance performance. J Strength Cond Res 2005; 19: 338-343

30 Pope $R$, Herbert $R$, Kirwan J. Effects of ankle dorsiflexion range and pre-exercise calf muscle stretching on injury risk in Army recruits. Aust J Physiother 1998; 44: 165-172

31 Pope RP, Herbert RD, Kirwan JD, Graham BJ. A randomized trial of preexercise stretching for prevention of lower-limb injury. Med Sci Sports Exerc 2000; 32: 271-277

32 Purslow PP. Strain-induced reorientation of an intramuscular connective tissue network: implications for passive muscle elasticity. J Biomech 1989; 22: 21-31

33 Radford JA, Burns J, Buchbinder R, Landorf KB, Cook C. Does stretching increase ankle dorsiflexion range of motion? A systematic review. $\mathrm{Br}$ J Sports Med 2006; 40: 870-875

34 Rosenbaum D, Hennig EM. The influence of stretching and warm-up exercises on Achilles tendon reflex activity. J Sports Sci 1995; 13: 481-490

35 Ryan ED, Beck TW, Herda TJ, Hull HR, Hartman MJ, Costa PB, Defreitas $J M$, Stout JR, Cramer JT. The time course of musculotendinous stiffness responses following different durations of passive stretching. J Orthop Sports Phys Ther 2008; 38: 632-639
36 Ryan ED, Beck TW, Herda TJ, Hull HR, Hartman MJ, Stout JR, Cramer JT. Do practical durations of stretching alter muscle strength? A doseresponse study. Med Sci Sports Exerc 2008; 40: 1529-1537

37 Thacker SB, Gilchrist J, Stroup DF, Kimsey CD. The impact of stretching on sports injury risk: a systematic review of the literature. Med Sci Sports Exerc 2004; 36: 371-378

38 Toft E, Espersen GT, Kålund S, Sinkjaer T, Hornemann BC. Passive tension of the ankle before and after stretching. Am J Sports Med 1989; 17: 489-494

39 Vanmechelen W, Hlobil H, Kemper HC, Voorn WJ, Dejongh HR. Prevention of running injuries by warm-up, cool-down, and stretching exercises. Am J Sports Med 1993; 21: 711-719

40 Wiktorsson-Möller M, Oberg B, Ekstrand J, Gillquist J. Effects of warming up, massage, and stretching on range of motion and muscle strength in the lower extremity. Am J Sports Med 1983; 11: 249-252

41 Wilson GJ, Elliott BC, Wood GA. Stretch shorten cycle performance enhancement through flexibility training. Med Sci Sports Exerc 1992; 24: $116-123$

42 Winchester JB, Nelson AG, Landin D, Young MA, Schexnayder IC. Static stretching impairs sprint performance in collegiate track and field athletes. J Strength Cond Res 2008; 22: 13-19

43 Witvrouw E, Mahieu N, Danneels L, McNair P. Stretching and injury prevention: an obscure relationship. Sports Med 2004; 34: 443-449

44 Woods $K$, Bishop P, Jones E. Warm-up and stretching in the prevention of muscular injury. Sports Med 2007; 37: 1089-1099 